\title{
Design and Development of Gearbox Loading and Unloading Machine
}

\author{
Mr. A L. Meshram', Ajay Kumar², Asad Ahmed ${ }^{3}$, Shakti Kumar ${ }^{4}$, Anshul Phopre ${ }^{5}$, \\ Shubham Kadu ${ }^{6}$ \\ ${ }^{1}$ Assistant Professor, ${ }^{23456}$ UG Students \\ Department of Mechanical Engineering, Nagpur Institute of Technology, Nagpur, India
}

\begin{abstract}
The objective of automation is to ease the movement and to increase the productivity of the system as it become the basic need of today's automobile industry and workshops to used mechanized system. Hence it is focused to attention on Automobile Services Centers for repairing LMV, State Transport bus uses, Trucks etc. and choose the problem of gearbox unloading for the project. Because of location of gearbox it takes, more time and more labor for detaching it form the engine. In the gearbox unloading machine consist a simple for bar mechanism formed by various links. The mechanisms mounted on a trolley made up of C-channel. The two pairs of heels are provided to the trolley. The link $C$-channel is having a fixture for holding the gearbox. The operation of this devise is simple. The operation will rotate the hand wheel and adjust the position of mechanism so that gearbox is held in fixture then lock the handle wheel. The gearbox will be detached from the engine. Afterwards rotate the hand wheel to lower down the gearbox for further repair.
\end{abstract}

Keywords- Chain, Engine, Gearbox, Worm

\section{INTRODUCTION}

I In the era of global market, we have to face a stiff competition in every field of life. Engineering industries and services sectors has to offer products and services at the lowest possible cost. This is which the important of productivity lies. The meaning of productivity is the use of available resources to the maximum extent to obtain the product at lowest cost. So, it is the basic need to focus attention on Automobile Services Centers for repairing LMV, State Transport bus uses, Trucks etc. and choose the problem of gearbox unloading for our project. Because of location of gearbox it takes, more time and more labor for detaching it form the engine. The gearbox unloading device is developed which saves both tie and work force, those helping the service for improving their productivity.

A differential pulley can lift very large [Mass/masses] a short distance. It consists of two fixed [pulley] of unequal radii that are attached to each other and rotate together, a single pulley bearing the load, and an endless rope looped around the pulleys. To avoid slippage, the rope is usually replaced by chain and the connected pulleys by sprockets. The two section of chain carrying the single pulley exert opposing and unequal torques on the connected pulleys, such that only the "difference" of these torques has to be compensated manually by pulling the loose part of chain.

In the gearbox unloading machine consist a simple for bar mechanism formed by various links. The mechanisms mounted on a trolley made up of C-channel. The two pairs of heels are provided to the trolley. The link C-channel is having a fixture for holding the gearbox. The four-bar mechanism is designed with suitable length of links so that are having a parallel motion i.e. for any position of mechanism the link will always remain in horizontal position. The horizontal position of link will ensure safe unloading of gearbox without any skidding. The four-bar mechanism is operated by driving the crank by worm and worm gearbox. A hand wheel operates the worm and worm gear box. The provision is made for locking the hand wheel with the help of pin.

The operation of this devise is simple. The operation will rotate the hand wheel and adjust the position of 
mechanism so that gearbox is held in fixture lock the handle wheel. The gearbox will be detached from the engine. Afterwards rotate the hand wheel to lower down the gearbox for further repair.

\section{METHOLOGY}

\section{WORM GEAR}

Many gears have an interesting property that no other gear set has the worm can easily turn the gear, but gear cannot turn the worm. This is because the angle on the worm is so shallow that when the gear tries to spin it. Their friction between the gear and the worm holds the worm in place.

\section{FOUR BAR MECHANISM}

A four-link mechanism with four revolute joints is commonly called four bar chain mechanism. A four-bar mechanism consists of four rigid link which are linked in the form of quadrilateral by four pin joints. A link that makes complete revolution is called crank, the link opposite to the fixed link is the coupler and forth link is a lever or rocker if oscillates or another crank if rotates

The working of gearbox unloading machine is very simple. When we rotate the handle in clockwise direction a drop arm is moves upward. As we know on drop arm a fixture is mounted through linkages, consequently fixture is also move in upward direction. When fixture reaches its position where the gearbox is situated, it holds the gearbox. Then by using handles locking system lock the fixture at a desired position. Remove the studs of gearbox carefully. Confirm the gearbox is properly held or not. Then remove the locking nut that is situated on handle in this way unlock the handle. After that rotate the handle in anticlockwise direction slowly guide lever, drop arm and fixture are goes down. Pull the machine, which is below the vehicle (bus, truck, car), and remove gearbox then repair it. After repairing mount gearbox on fixture, rotate handle in clockwise direction when it reaches at appropriate position, and lock handle. Fix the studs of gearbox properly. After confirm the gearbox is fixed remove the machine.

\section{CONSTRUTION AND FABRICATION}

The gear box unloading machine consist of a c channel section base on which gear box is mounted at one end and on the other end of gear box fixture(bracket) is mounted. A drop arm is connecting by a nut for avoiding slipping and upper portion of the arm is fixed by means of welding. On the top side of arm, a half-circular fixture is made up from MS (mild steel) flat5*20. A guide lever is welded on base through a horizontal bar and upper end is connecting to the lower end of fixture. A circular handle is connected to worm shaft of steering gear box. On the handles periphery a small hole is drilled to locking purpose by using locking nut. Four wheels are provided below the base for transfer unloading gearbox from one place to another place. Following parts are provided with mechanism.

1) BASE: Base is important part of machine. It is also in a channel section. Nevertheless, it is not inverted like fixture base. On the base worm and worm wheel mechanism is connected. It supports guide lever, worm and worm wheel mechanism also.

2) FIXTURE OF GEAR BOX (BRACKET): It is the upper of the machine, used as sheet of gear Box. It has a parallel motion so that Gear Box is not tilt. It is made from mild steel flat plates.

3) HANDLE: Handle is circular in shape made from mild steel plate, which has thickness $5 \mathrm{~mm}$. on handles periphery small holes are provided for locking purpose. Handle is welded to worm shaft.

4) WHEELS: Wheels are the circular shape parts of the machine use for the movement of the machine.

\section{DESIGN \& CALCULATION}

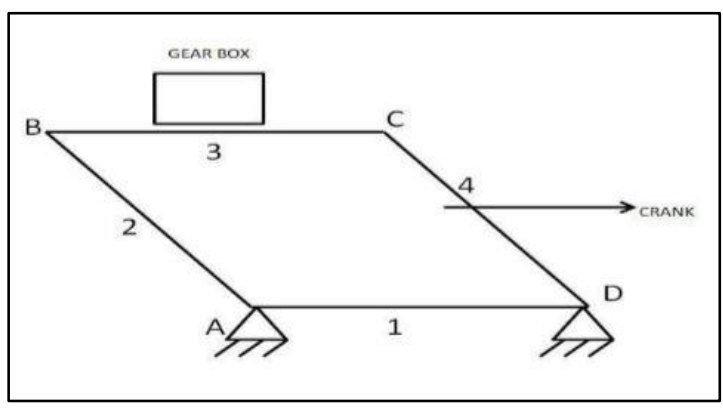

Fig. 1- four bar mechanism

$$
\begin{aligned}
\text { Degree of freedom }(\mathrm{F}) & =3(\mathrm{~N}-1)-2 * \mathrm{P} 1-\mathrm{P} 2 \\
& =3(4-1)-2 * 4-0 \\
& =1
\end{aligned}
$$

FORCE ANALYSIS 


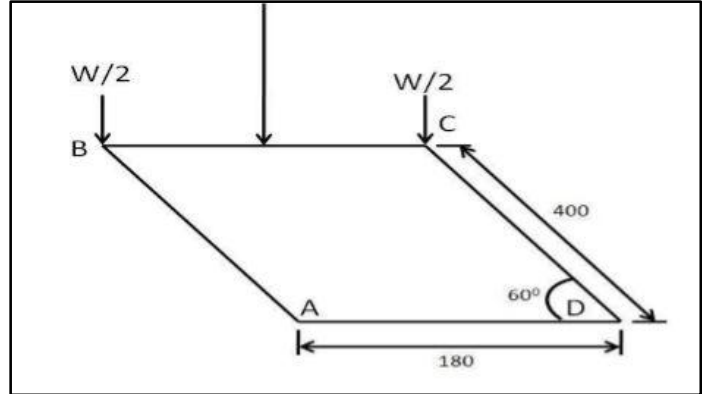

$$
\begin{aligned}
& \mathrm{M}=500 \mathrm{Kg} \\
& \mathrm{W}=\mathrm{M} \times \mathrm{g} \\
& \mathrm{W}=500 \times 9.81 \\
& =4905 \mathrm{~N} \\
& \mathrm{~W}=5000 \mathrm{~N}
\end{aligned}
$$

The load is distributed on two links AB \& CD

We consider a load on one link is

Load on Link AB $=5000 / 2$

$=2500 \mathrm{~N}$

$\mathrm{Wf}=5000 / 2=2500 \mathrm{~N}$

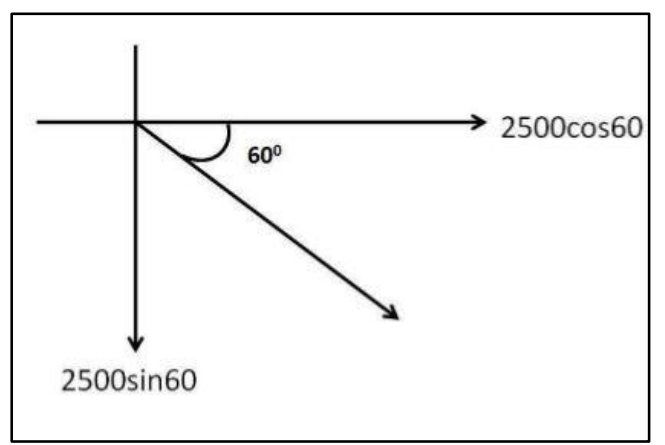

Fig 3: Inclined force acting on link $\mathrm{AB} \& \mathrm{CD}$

$\mathrm{Fx}=1250 \mathrm{~N}$

$\mathrm{Fy}=2165 \mathrm{~N}$

$\mathrm{R}=\sqrt{ }(1250) 2+(2165.063) 2$

$=2500 \mathrm{~N}$

$\sigma c=\mathrm{wf} / \mathrm{A}$

$$
=22.10 \mathrm{~N} / \mathrm{mm}^{2}
$$

Induced stresses in link is safe

Force acting on pin A, B, C \& D

$\mathrm{fxp}=2500 \cos 60$

$$
=1250 \mathrm{~N}
$$

fyp $=2500 \sin 60$

$$
=2165.063 \mathrm{~N}
$$

Resultant load acting on pin

$\mathrm{Rp}=\sqrt{ }(1250) 2+(2165.063) 2$

$$
=2500 \mathrm{~N}
$$

Shear stresses in pin

$$
\begin{aligned}
& =22.10 \mathrm{~N} / m m 2 \\
\mathrm{WDL} & =5000 \mathrm{~N}-\mathrm{mm} \\
& =5000 \times 20 \\
& =100000 \mathrm{~N}
\end{aligned}
$$

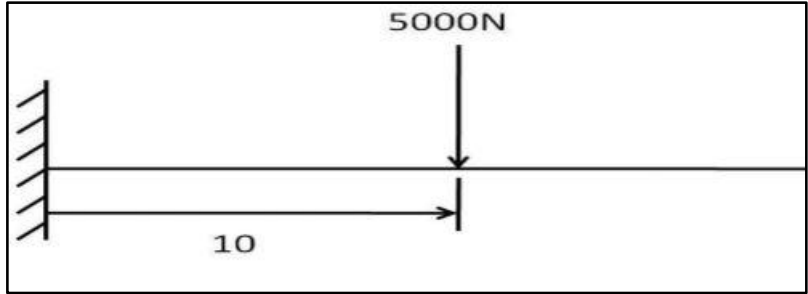

Fig 4: Bending In Pin

$\mathrm{M}=$ bending in pin

$$
=100 \times 104 \text { N-mm }
$$

Section modulus of pin

$Z=(\pi / 32) X d 4$

$Z=(\pi / 32) \times 124$

$\mathrm{Z}=2035.75 \mathrm{~mm} 4$

Bending stresses induced in link BC

$\sigma \mathrm{b}=\mathrm{M} / \mathrm{Z}$

$\sigma \mathrm{b}=491.21 \mathrm{~N} / \mathrm{mm} 2$

Stress in pin $=491021 \mathrm{~N} / \mathrm{mm} 2$

Torque required unloading the gear box

$\mathrm{T}=5000 \mathrm{X} 1200$

$=65 \times 105 \mathrm{~N}-\mathrm{mm}$

WORM AND WORM WHEEL

weight $500 \mathrm{~kg}$

$$
=9.81=4905 \mathrm{~N}
$$

Power $=5.136 \mathrm{KW}=6 \mathrm{KW}$

By interpolation method:

$\begin{array}{lll}\text { POWER } & \mathrm{Nw} & \mathrm{Ng} \\ 30 & 1440 & 40 \\ 22 & 3450 & 144 \\ 6 & \mathrm{X} & \mathrm{Y}\end{array}$

For $6 \mathrm{kw}$ :

$\mathrm{Nw}=940+280 / 2=610 \mathrm{rpm}$

$\mathrm{Ng}=8+43.2 / 2=25.6 \mathrm{rpm}$

A] static design criteria:

$\mathrm{Ft} \leq \mathrm{Fb}$

1] $\mathrm{Ft}=\mathrm{Pd} / \mathrm{Vp}$

$\mathrm{Pd}=\mathrm{P} * \mathrm{~K} 1=10.5 \mathrm{kw}$

$\mathrm{Vp}=\Pi . \mathrm{Dg} . \mathrm{Ng} / 60 * 1000=0.06 \mathrm{~m}$

$\mathrm{Ft}=10.5^{*} 10^{\wedge} 3 / 0.06 \mathrm{~m}$

2] $\mathrm{FB}=$ So.Y.Cv.b.m

assume SAE2320 for worm \& SAE65

Ph bronze for gear

$\mathrm{FB}=33.348 * 0.74 *(7.47 \mathrm{~m}+6.25) \mathrm{m}$

$$
=186.83 \mathrm{~mm}+156031 \mathrm{~m} \text {. }
$$

From equation (1) \& (2)

$175^{*} 10^{\wedge} 3 / \mathrm{m}=186.83 * \mathrm{~m}^{\wedge} 2+156.37 \mathrm{~m}$

$\mathrm{m}=9.51 \mathrm{~mm}$

Select standard $\mathrm{m}$ value $=10 \mathrm{~mm}$

B] WORMING \& HEATING TREATMENT 


\section{www.ijies.net}

$\mathrm{Fd} \leq \mathrm{Fw}$

$$
\text { 1] } \begin{aligned}
\mathrm{Fd} & =\mathrm{Ft} / \mathrm{cv}=23.33 * 10^{\wedge} 3 \\
\text { 2] } \mathrm{FW} & =\mathrm{Dg}^{*} \mathrm{~b} * \mathrm{~K} 2 \\
& =26880 \mathrm{~N}
\end{aligned}
$$

Hence design is safe.

\section{C] HEAT GENERATION / DESSIPITED DESIGN :}

$\mathrm{Q} 1 \leq \mathrm{Q} 2$

1] $\mathrm{Q} 1=(1-\mathrm{n}) . \mathrm{Pr}$

Calculated other values from data book

$\theta=18.98^{\circ}$

$\mathrm{Vr}=40.5 \mathrm{~m} / \mathrm{min}$

$\mathrm{U}=0.027 \eta \dot{~}$

$$
=0.91
$$

$\mathrm{Q} 1=0.54 * 10^{\wedge} 3$ watt

$\mathrm{Q} 2=\mathrm{K} . \mathrm{A} . \Delta \mathrm{T} \quad \mathrm{K}=0.4 * 10^{\wedge}-3 \mathrm{w} / \mathrm{mm}^{\wedge} 2 \dot{\mathrm{C}}$

$\mathrm{Lw}=142.62 \mathrm{~mm}$

$\mathrm{A}=183808.1 \mathrm{~mm}^{\wedge} 2$

$\mathrm{Q} 2=73.5 * \Delta \mathrm{T}$

From equation (3) \& (4)

$\Delta \mathrm{T}=7.34 \dot{\mathrm{C}}$

Check: $\Delta \mathrm{T}<40 \dot{\mathrm{C}}$ std. value from data book

Hence design is safe.

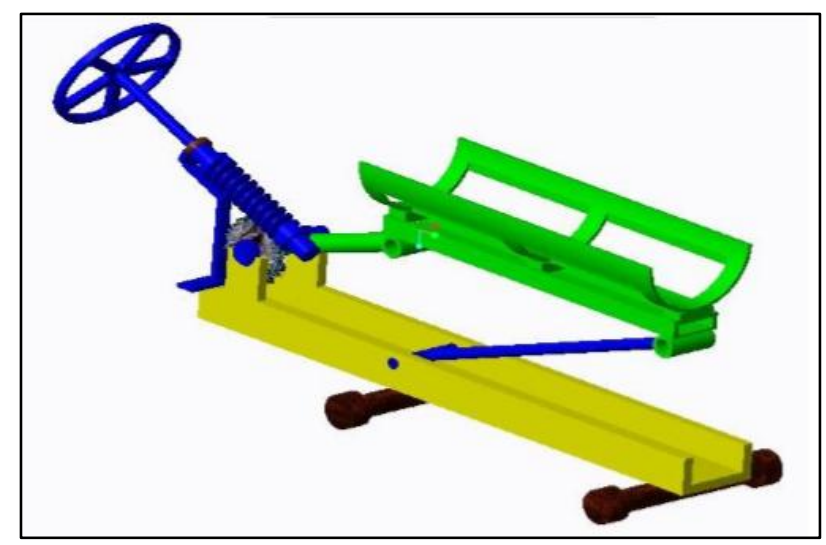

Fig 5: 3 D model

\section{RESULT}

The proposed model can unload the gear box and bear its weight easily and thus reduce the time, labor, cost and increase work efficiency. This model seems to be more economical and reliable than the previous one i.e. chain pulley. It reduce the human efforts required to unload gear box. It also reduces time and cost thus it is more suitable and profitable method than any other which is used for gear box loading and unloading purpose.

\section{CONCLUSION}

The design of Gearbox Loading and Unloading Machine is successful and this can be adopted in practice instead of chain and pulley which saves time and more labor for detaching it from engine. Thus, gearbox unloading device is developed which saves both time and workforce, which enables the service center for improving their work efficiency.

\section{FUTURE SCOPE}

In future we can modify the system using atomization with the help of PLC or robotics etc .

\section{REFERENCES}

[1] .R. A. Graveling, A. S. Melrose and M. A. Hanson. Epidemiologic evidence on manual handling as a risk factor for back disorder : a systematic review. Int J Ind Ergon 1999;24:389-404

[2] Tony Wynn "A review of research on techniques for lifting low lying objects. Evidence for a correct technique. "Work 2002; 20:83-96.

[3] John Howard. A review of research on techniques for lifting lowlying objects, Evidence for correct technique. Work 2002; 20:8396

[4] Chia Chang Lee "HYDRAULIC LIFTING DEVICE" 1993, Variable from research paper Driving action of crank arm.

[5] Olavi Jussi "LIFTING MACHINERY" 1992, Variable from research paper Mechanism of lifting of load with the help of arm.

[6] Jarmo Eloranta "LIFTING MECHANISM OF JACK UP PLATFORM" 1987 Variable from research paper Lifting using worm gear mechnism.

[7] Olavi Jussila "LIFTING TOOL FOR SERVICING OF WING TURBINE GEAR BOX COMPONENT" 1939 Variable from research paper Lifting mechanism for higher height.

[8] 8. "DESIGN DATA BOOK FOR MACHINE ELEMENTS" 2013 By B. D. Shiwalkar. 